\title{
Effective use of cyclosporin in sarcoidosis: a treatment strategy based on computed tomography scanning
}

\author{
C.A. O'Callaghan*, A.U. Wells*, A. Lalvani*, P.D. Dhillon**, D.M. Hansell*, D.N. Mitchell*
}

Effective use of cyclosporin in sarcoidosis: a treatment strategy based on computed tomography scanning. C.A. O'Callaghan, A.U. Wells, A. Lalvani, P.D. Dhillon, D.M. Hansell. D.N. Mitchell. CERS Journals Ltd 1994.

ABSTRACT: Cyclosporin was used successfully in a patient with severe pulmonary sarcoidosis, a poor response and unacceptable side-effects from corticosteroid therapy.

Computed tomography (CT) scanning initially suggested reversible disease, and subsequently detected improvement earlier than other indices of disease activity. This information was critical in the decision to commence and to continue cyclosporin. The literature on the use of cyclosporin in sarcoidosis is reviewed. Eur Respir J., 1994, 7, 2255-2256.
*Royal Brompton National Heart and Lung Hospital, London UK. **Kings Cross Hospital, Dundee, UK.

Correspondence : D.N. Mitchell

Royal Brompton National Heart and Lung Hospital, London SW3 6NP

UK.

Keywords: Cyclosporin, sarcoidosis, X-ray computed tomography

Received: February 81994

Accepted after revision June 101994
We describe a case which highlights two issues: the use of cyclosporin and the value of computed tomography (CT) scanning in appropriately selected patients with sarcoidosis.

\section{Case report}

A 37 year old man presented with cough, arthralgia, skin lesions, a bilateral interstitial infiltrate on chest radiography and restrictive pulmonary function tests. Sarcoidosis was diagnosed on bronchial biopsy and prednisolone was initiated at $40 \mathrm{mg}$ daily. Over the next 2 yrs treatment of the patient was complicated by marked weight gain and avascular necrosis of both femoral heads requiring bilateral total hip replacements. A maintenance hydrocortisone dosage of $20 \mathrm{mg}$ daily was required to prevent the resurgence of pulmonary disease.

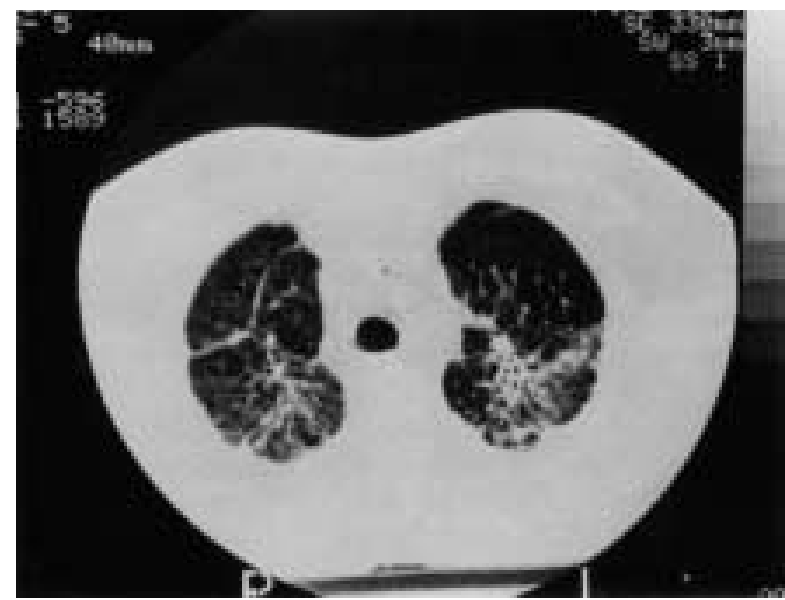

Fig. 1. - A $3 \mathrm{~mm}$ thoracic computed tomography (CT) section taken before cyclosporin therapy; the predominant abnormality is a ground glass appearance involving most of the lung parenchyma.
At referral, $5 \mathrm{yrs}$ from presentation, the patient was dyspnoeic on minimal exertion and investigations disclosed mild liver dysfunction. A chest radiograph showed a reticulonodular pattern with no ground glass component, but on CT scanning (fig. 1) a prominent ground glass pattern was seen. Respiratory function tests showed moderate restriction with airflow limitation (forced expiratory volume in one second/forced vital capaci $\left(\mathrm{FEV}_{1} / \mathrm{FVC}\right)=1.66 /$ $2.72 l$ ). Because of the severe steroid side-effects, cyclosporin was initiated $\left(180-450 \mathrm{ng} \cdot \mathrm{ml}^{-1}\right)$.

At 2 months, the patient's exercise tolerance had improved and liver function was normal. A marginal improvement in lung function did not reach significance $\left(\mathrm{FEV}_{1} / \mathrm{FVC}=1.78 / 2.82 l\right)$. Chest radiograph appearances were unchanged, but a repeat CT scan showed unequivocal regression of disease (fig. 2). Cyclosporin was, therefore, continued and the trend in respiratory function

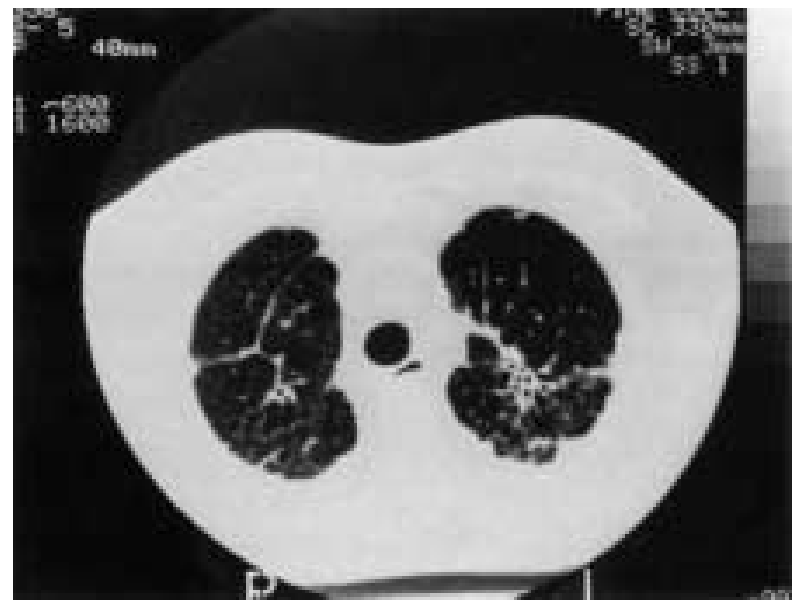

Fig. 2. - An anatomically comparable section taken 2 months after starting cyclosporin; there is marked resolution of the ground glass changes. 
subsequently reached significance at 4 months $\left(\mathrm{FEV}_{1} /\right.$ $\mathrm{FVC}=1.84 / 3.05 l)$ and was maintained, despite withdrawal of hydrocortisone at this time.

\section{Discussion}

The literature contains 24 cases of sarcoidosis treated with cyclosporin. [1-8]. There are good theoretical reasons for evaluating the use of cyclosporin in sarcoidosis [8]. Active pulmonary sarcoidosis is characterized by infiltration with proliferating T-lymphocytes. Interleukin-2 (IL-2) is associated with T-helper lymphocyte activation and proliferation. Cyclosporin inhibits IL-2 gene expression and T-helper lymphocyte proliferation. The mechanism of this action involves effects on protein transcription factors regulating the IL-2 gene [9, $10]$.

A study of cyclosporin in uncomplicated pulmonary disease comprised eight cases [8]. No clear clinical benefit was seen. Cyclosporin suppressed in vitro IL-2 release and the proliferation of T-lymphocytes derived from bronchoalveolar lavage of these patients, but failed to suppress them in vivo. The other 16 cases were given cyclosporin because of uncontrollable disease on steroid therapy or unacceptable steroid side-effects. Nine cases showed objective clinical improvement, with subjective improvement in a further two. In 12 patients, a fall in bronchoalveolar lavage lymphocyte count occurred. In two cases, life-threatening endobronchial lesions regressed only with cyclosporin $[1,2]$.

Responsiveness to cyclosporin may be dependent on dose. Where doses were cited, objective improvement was seen in all five cases, including our own, treated with a high dose range $\left(150-500 \mathrm{ng} \cdot \mathrm{ml}^{-1}\right)[1,5]$, but in only $2 / 16$ cases treated with a low dose range (100-200 $\left.\mathrm{ng} \cdot \mathrm{ml}^{-1}\right)[2,4,8]$. The dose required to prevent activation of T-cells is lower than that required to inhibit previously activated T-cells. For this reason, cyclosporin is administered before organ transplantation and is highly effective in preventing organ rejection, characterised by T-cell activation, but not in treating rejection once it is established. High doses may be necessary to deal with the activated T-cells in sarcoidosis, though it may prove possible to use lower doses to maintain remission analogous to organ grafting regimens. The inconsistency between in vitro and in vivo results in the study by MARTINET et al. [8] may reflect a higher effective dose delivery in vitro.

Thoracic CT scanning made a major contribution to the management of our patient, as it identified an increased likelihood of responsiveness to therapy. Alveolar consolidation, nodularity and a ground glass pattern on CT scanning have recently been shown to indicate reversible disease in sarcoidosis [11]; in our patient, a prominent ground glass appearance was seen on CT, but not on chest radiography. In most patients with uncomplicated pulmonary sarcoidosis, CT scanning adds little to management; a response to therapy is the rule and CT scanning, which is expensive and carries a significant radiation burden, cannot be justified. However, this case highlights the clinical utility of CT in pulmonary sarcoidosis when the decision to treat with potentially toxic therapy is not straightforward.

In addition, CT scanning may detect changes in disease severity with treatment, which is particularly useful when changes in functional indices are inconclusive. The superior sensitivity in detecting change, of CT scanning compared to chest radiography and lung function indices, has recently been documented in fibrosing alveolitis [12] and merits further study in sarcoidosis. In our patient, a rise in lung volumes of less than $10 \%$ at two months could have been attributed either to regression of pulmonary disease or to technical factors in laboratory measurement. Serial CT scanning was pivotal to our management, demonstrating unequivocal improvement before this was apparent in functional measurements, and encouraging us to continue cyclosporin.

The role of cyclosporin and the clinical utility of CT scanning in sarcoidosis merit further evaluation.

\section{References}

1. Rebuck AS, Stiller CR, Braude AC, Laupache A, Cohen $\mathrm{RD}$, Chapman KR. Cyclosporin for pulmonary sarcoidosis. Lancet 1984; 1: 1174.

2. Rebuck AS, Sander BRE, MacFadden DK, Man SFP, Cohen RD. Cyclosporin in pulmonary sarcoidosis. Lancet 1987; 1: 1486.

3. Sandor V, Andras K, Sandor S, Piroska O. A sarcoidosis Ciklosporin-A kezeleserol. Orvosi Hetilap 1988; 129 (38): 2029-2031.

4. York EL, Kovithavongs T, Man P, Rebuck AS, Sproule BJ. Cyclosporin and chronic sarcoidosis. Chest 1990; 98: 1026-1029.

5. Kavanaugh AF, Andrew SL, Cooper B, Lawrence EC, Huston DP. Cyclosporin therapy of central nervous system sarcoidosis. Am J Med 1987; 82: 387.

6. Hammond JMJ, Bateman ED. Successful treatment of life-threatening steroid-resistant pulmonary sarcoidosis with cyclosporin in a patient with systemic lupus erythematosus. Respir Med 1990; 84: 77-80.

7. Cunnah D, Chew S, Wass J. Cyclosporin for central nervous system sarcoidosis. Am J Med 1988; 85: 580581.

8. Martinet Y, Pinkston P, Saltini C, Purzem J, MullerQuernheim J, Crystal RG. Evaluation of the in vitro and in vivo effects of cyclosporin on the lung T-lymphocyte alveolitis of active pulmonary sarcoidosis. Am Rev Respir Dis 1988; 138: 1242-1248.

9. O'Keefe SJ, Tamura J, Kincaid RL, Tocci MJ, O'Neill EA. FK-506 and CsA sensitive activation of the interleukin-2 promoter by calcineurin. Nature 1992; 357 (6380): 692-694.

10. Jain J, McCaffrey PG, Miner ZKT et al. The T-cell transcription factor NFATp is a substrate for calcineurin and interacts with Fos and Jun. Nature 1993; 365(6444): 352-355.

11. Brauner MW, Lenoir S, Grenier P, Cluzel P, Battesti JP, Valeyre D. Pulmonary sarcoidosis: CT assessment of lesion reversibility. Radiol 1992; 182: 349-354.

12. Wells AU, Hansell DM, Rubens MB, Black CM, Dubois RM. The clinical utility of thin section computed tomography in the detection of changes in disease severity in fibrosing alveolitis. Am Rev Respir Dis 1993; 147: A593. 